\title{
Nuclear microscopic studies of inclusions in natural and synthetic emeralds
}

\author{
K. N. Yu, ${ }^{1 *} \dagger$ S. M. Tang ${ }^{1}$ and T. S. Tay ${ }^{2}$ \\ ${ }^{1}$ Department of Physics, National University of Singapore, Kent Ridge, Singapore 119260 \\ ${ }^{2}$ Far East Gemological Laboratory, 19, Tanglin Road, \#B2-02, Tanglin Shopping Centre, Singapore 247909
}

\begin{abstract}
Maps recorded by micro-proton-induced x-ray emission (micro-PIXE) were obtained for different chemical elements for natural and synthetic emeralds. Eighty pieces of natural and synthetic stones were examined. The following inclusions and minerals were observed: (1) color zoning/elemental zoning; (2) brine components; (3) calcite/dolomite; (4) chromite/magnetite; (5) pyrite and the accompanying sphalerite/wurtzite; (6) mica (biotite, phlogopite and muscovite); (7) feldspar (orthoclase and anorthite of plagioclase); (8) flux residues/nutrient residues; and (9) seed crystal. These (a) demonstrated the power of micro-PIXE in revealing inclusions in emeralds, which was useful for easy and unambiguous identification, and which made the identification of inclusions in rough stones possible; (b) provided some criteria for discrimination between natural and synthetic emeralds; and (c) gave the source of some chemical elements, so that their presence derived from the PIXE spectra would be further supported (e.g. $\mathrm{Cl}$ in the brine component in natural and flux grown emeralds; Cl was previously said to be present only in hydrothermal grown emeralds). Furthermore, the present work showed the power of micro-PIXE in the in situ study of minerals. Copyright $@ 2000$ John Wiley \& Sons, Ltd.
\end{abstract}

\section{INTRODUCTION}

Emerald is the green variety of the mineral called beryl with the chemical composition of beryllium aluminum silicate, $\mathrm{Be}_{3} \mathrm{Al}_{2}\left(\mathrm{SiO}_{3}\right)_{6}$. Other varieties of beryls include aquamarine, morganite, heliodor, vanadium beryl, red beryl, yellow beryl, violet beryl, colorless beryl, etc. In the early 1980s, relatively comprehensive non-destructive analyses of emeralds were carried out using energydispersive $\mathrm{x}$-ray fluorescence (EDXRF) and electron microprobe methods, ${ }^{1,2}$ and valuable results were obtained.

In the present work, the nuclear microscopic features recorded using micro-PIXE were used for studying natural and synthetic emeralds. The objectives that were achieved in the present work are as follows.

First, we demonstrated the power of micro-PIXE in revealing inclusions in emeralds. The optical-microscopic examination of inclusions is by far the most accurate method among traditional techniques in discriminating between natural and synthetic emeralds, and between natural emeralds from different localities. However, some inclusions are extremely difficult, if not impossible, to observe and identify, and some inclusions can easily be confused with others. In the special case of rough stones, information on inclusions will be totally lacking based on traditional methods. Micro-PIXE maps are useful for the easy identification of inclusions, and are essential for the

\footnotetext{
* Correspondence to: K. N. Yu, Department of Physics and Materials Science, City University of Hong Kong, Tat Chee Avenue, Kowloon Tong, Hong Kong.

$\dagger$ Permanent address: Department of Physics and Materials Science, City University of Hong Kong, Tat Chee Avenue, Kowloon Tong, Hong Kong.
}

identification of inclusions in rough stones. It is true that one cannot always decide on the mineralogy unambiguously from the chemical composition alone derived from micro-PIXE, e.g. in theory $\mathrm{CaCO}_{3}$ can be aragonite or calcite. In these cases, traditional knowledge in gemmology can help, e.g. calcite is one of the commonest inclusions in emerald whereas aragonite is not. Nevertheless, these cases should be handled with caution.

Second, we provided some criteria for discrimination between natural and synthetic emeralds; most of these were in fact due to the presence of different inclusions for different emeralds.

Third, we gave the source of some chemical elements. In doing so, their presence derived from the PIXE spectra would be further supported. In previous investigations, $\mathrm{Cl}$ was not detected in all natural emeralds ${ }^{1,2}$ but was detected in all the hydrothermal emeralds ${ }^{2}$ and was believed to come from the chloride hydrate $\left(\mathrm{CrCl}_{3} \cdot 6 \mathrm{H}_{2} \mathrm{O}\right)$ used to supply $\mathrm{Cr}$ as a coloring agent. ${ }^{3}$ This is surprising because $\mathrm{Cl}$ should be present in emerald samples. It is known that the well-known three-phase inclusions in Colombian stones contain brine and a crystal which is likely to be halite $(\mathrm{NaCl})$ [and it is assumed that there is also some subordinate sylvite $(\mathrm{KCl})$; the mixture of sylvite and halite is called sylvinite] when it is cubic, or calcite $\left(\mathrm{CaCO}_{3}\right)$ or dolomite $\left(\mathrm{CaMg}\left[\mathrm{CO}_{3}\right]_{2}\right)$ when it is rhombohedral, and these cavities were originally filled with a single-phase brine with a salt content of approximately $40 \mathrm{wt} \% \mathrm{Cl}$ and $\mathrm{Na}$ with $\mathrm{Ca}, \mathrm{K}$, etc. ${ }^{4}$ For synthetic stones, information on the nutrient input can also be revealed.

Finally, we demonstrated the power of micro-PIXE in the in situ study of minerals. Theoretically, microPIXE should be a superb method for studying minerals. It is non-destructive, which keeps the mineral inclusions intact and free from contamination or chemical changes 
on contact with the polishing machine or on exposure to air or water vapor. Furthermore, it is more economical as larger amounts of stones can be borrowed from dealers for the study. Electron microprobe analysis is the only other non-destructive method which has a scanning feature. Micro-PIXE has the advantages over electron microprobe analysis that it collects properties of the stone from areas down to greater depths and has much higher sensitivity (much lower limits of detection).

\section{EXPERIMENTAL}

\section{Equipment}

The nuclear microscopy facility employed for the present research comprised a 2.5 MV Van de Graff accelerator and coupled triplet of magnetic quadrupole lenses. The data acquisition system was PC-based and operated under Windows. It allowed a target area of any shape to be defined easily for imaging. Details of the experimental set-up can also be found elsewhere. ${ }^{5}$

Our study involved the use of two techniques simultaneously, namely PIXE and Rutherford backscattering spectroscopy (RBS). The former was employed to obtain the elemental compositions of the specimens and the latter for determining the specimens' matrix and estimating the total charge of irradiation. An $\mathrm{Si}(\mathrm{Li})$ detector of active area $71 \mathrm{~mm}^{2}$ with a $12 \mu \mathrm{m}$ thick beryllium window was used for $\mathrm{x}$-ray detection and a PIPS detector of $25 \mathrm{~mm}^{2}$ sensitive area was used for counting the backscattered protons.

\section{Samples}

For natural emeralds, we had 20 specimens from Colombia, six from Pakistan, 25 from Zambia and five from Brazil. For synthetic emeralds, we had five Chatham, four Gilson, five Russian, two Taiwan and one Lennix stones which were manufactured using the flux method and three Biron, five Russian and one Lechleitner stones which were manufactured using the hydrothermal method.

The stones were mounted on a layer of Blu-Tack adhered to a copper sample holder of size $4 \times 2 \mathrm{~cm}$ in such a way that a flat surface of each stone was facing upwards, and all these surfaces of the stones were on the same plane to facilitate the focusing of the proton beam on their surfaces. For stones with emerald cuts, the table facet was chosen as the surface for irradiation; for cabochons, the base was used; and for rough stones, a flat surface was employed. Special care was taken not to contaminate this surface with the Blu-Tack. If it was contaminated, structures characteristic of the Blu-Tack would appear on the maps of the elements. Prior to the measurements, these mounted stones together with the Blu-Tack were coated with a thin layer of carbon to prevent the accumulation of charges on their surfaces during the proton bombardment, which would increase the background for the detection of $\mathrm{x}$-ray signals.

\section{Method}

Protons of $2 \mathrm{MeV}$ were used for excitation and a Kapton filter of thickness $50 \mu \mathrm{m}$ was placed between the specimen and the detector to cut down the aluminum and silicon signals in order to enhance the detectability of the heavier trace elements. The typical beam spot size was about $1 \mu \mathrm{m}$. In addition to the PIXE and RBS spectra, elemental maps were also recorded for a number of chemical elements of interest, including $\mathrm{Si}, \mathrm{S}, \mathrm{Cl}, \mathrm{K}, \mathrm{Ca}, \mathrm{Ti}, \mathrm{V}, \mathrm{Cr}, \mathrm{Fe}$, $\mathrm{Co}, \mathrm{Ni}, \mathrm{Cu}, \mathrm{Zn}, \mathrm{Ga}, \mathrm{Rb}$, Mo, Cs, Pt, Au and Pb. Before each run with an emerald sample, data were recorded for a few minutes so that the elemental maps could be examined carefully. A user-defined raster of any shape could be selected for the actual irradiation. The silicon map gave an outline of the emerald so that it was easy to ensure that the irradiation was on the stone itself. The silicon intensities would help identify a flat surface which could be chosen for irradiation; a non-flat surface, such as the incorporation of a tilted facet, would lead to an image with non-uniform silicon intensities. The imaging time for our samples was around 10-20 min, depending on the count rate, but the actual time needed for a real life test may be shorter.

\section{INCLUSION ANALYSIS}

Different types of known inclusions relevant to the studies on emeralds which can be identified from our micro-PIXE maps include the following: (1) color zoning/elemental zoning; (2) brine; (3) calcite/dolomite; (4) chromite/magnetite; (5) pyrite; (6) mica/biotite; (7) feldspar; (8) flux/nutrient residues; and (9) seed crystal. Some of these inclusions were identified in our sample stones under the optical microscope. Sample micro-PIXE results for some of the stones in which micro-PIXE identifications were made will be discussed under different headings for inclusions. The corresponding micro-PIXE maps are shown in Figs 1-13, grouped according to the sources of the emeralds. The definitions, information and discussions of these inclusions are given in the following paragraphs. Finally, as a summary, the criteria for the identification of inclusions in emeralds for the traditional optical microscopic method and for the nuclear microscopic (micro-PIXE) method, are presented in Table 1.

\section{Color zoning}

Color zoning is defined to be zoning of the chromophore elements $\mathrm{Cr}, \mathrm{V}$ and $\mathrm{Fe}$ (regional difference in intensities) in the PIXE maps. The correspondence between the color zoning and the zoning of the above elements was
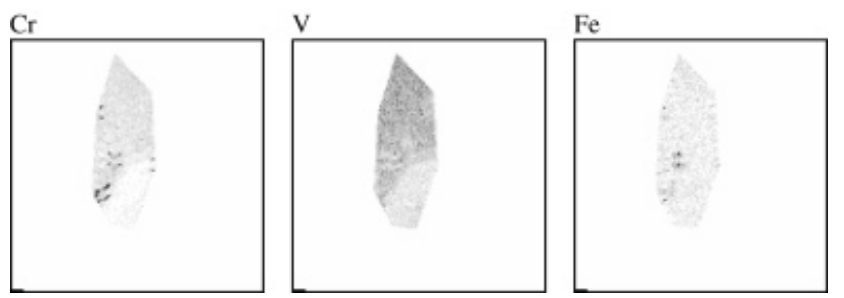

Figure 1. Nuclear microscopic maps of a Colombian emerald (CB9). Zoning of $\mathrm{Cr}$ and $\mathrm{V}$ is identified but seemingly not with $\mathrm{Fe}$. Charge $=0.075 \mu \mathrm{C}$; the square grid represents an area of $2 \times 2 \mathrm{~mm}$. 

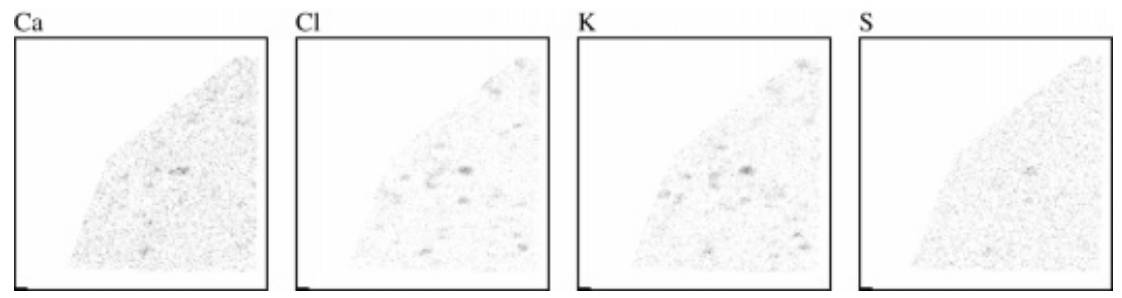

Figure 2. Nuclear microscopic maps of a Colombian emerald (CB17). Brine components are identified which show strong correlations between $\mathrm{Cl}$ and $\mathrm{K}$, and weaker correlations with $\mathrm{Ca}$ and $\mathrm{S}$. Charge $=0.033 \mu \mathrm{C}$; the square grid represents an area of $3.6 \times 3.6 \mathrm{~mm}$.
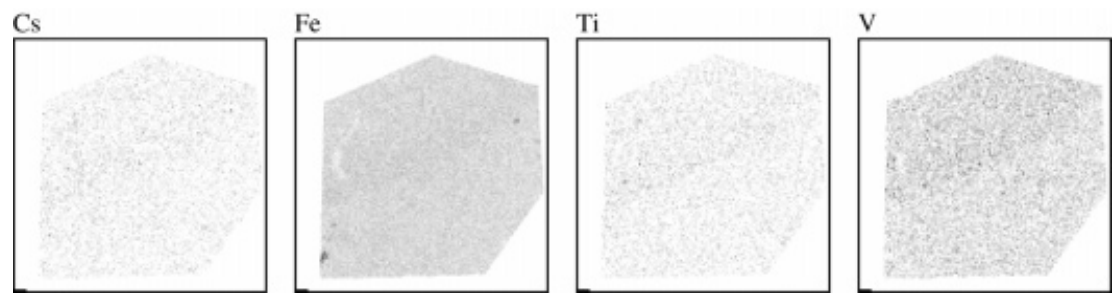

Figure 3. Nuclear microscopic maps of a Zambian emerald (ZB9). Zoning of elements is obvious in the maps of $\mathrm{Cs}, \mathrm{Fe}, \mathrm{Ti}$ and $\mathrm{V}$. Charge $=0.062 \mu \mathrm{C}$; the square grid represents an area of $3.6 \times 3.6 \mathrm{~mm}$.
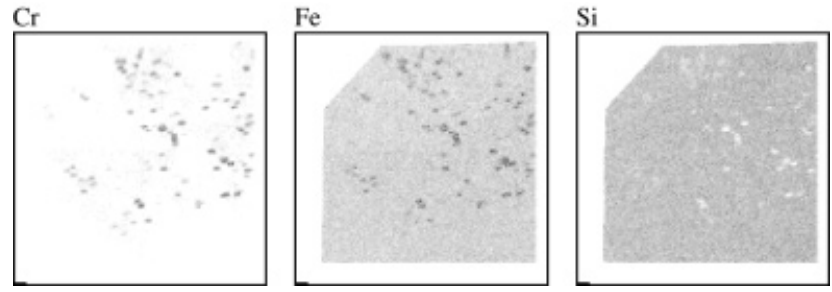

Figure 4. Nuclear microscopic maps of a Zambian emerald (ZB11). The maps of $\mathrm{Cr}$ and $\mathrm{Fe}$ show the presence of chromite and magnetite. The anticorrelation between the pattern with $\mathrm{Si}$ implies that this set of inclusions was rather near the surface. Charge $=0.063 \mu \mathrm{C}$; the square grid represents an area of $3.6 \times 3.6 \mathrm{~mm}$.

confirmed with the help of the optical microscope and after the examination of a large number of emeralds. Elemental zoning is defined to be zoning of the nonchromophore elements. This feature can only be confirmed optically if a color zoning occurs in the same regions.

It was found that color zoning occurred in most of the natural emeralds irrespective of their localities. In contrast, color zoning was not identified in any of our synthetic samples although there were also reports saying that different color zones had been identified in synthetic emeralds (e.g. Ref. 6). Zoning of $\mathrm{Cr}$ and $\mathrm{V}$ was identified but seemingly not with $\mathrm{Fe}$ in the Colombian stone CB9
(Fig. 1). This is not consistent with the proposal that the elements of chromophores include $\mathrm{Cr}, \mathrm{V}$ and $\mathrm{Fe} .{ }^{4}$ In fact, two sets of color zonings revealed by the chromophore elements $\mathrm{Cr}$ and $\mathrm{V}$ likely to be hexagonal could be seen. The first set consisted of a sharply defined paler core at the lower right region of the scan surrounded by a more saturated shell. This could also be seen optically. The second set consisted of alternate bands above the pale core mentioned above. Color zoning and elemental zoning were observed in the Pakistan stone PK1 (Fig. 7), which consisted of a sharply defined paler hexagonal core at the lower left region of the scan surrounded by a more saturated shell, and were also seen optically. The paler region contained less $\mathrm{Cr}, \mathrm{V}, \mathrm{Fe}, \mathrm{Ti}$ and $\mathrm{Cs}$. A cloudy color zoning was observed in the $\mathrm{Cr}$ map for the Pakistan stone PK4 (Fig. 8), which could also be identified under the microscope. However, the cloudy color zoning was not readily observable in the maps of other possible chromophore elements $\mathrm{V}$ and Fe. Zoning of elements was obvious in the maps of $\mathrm{Cs}, \mathrm{Fe}, \mathrm{Ti}$ and $\mathrm{V}$ for the Zambian stone ZB9 (Fig. 3). This also showed that these elements were somewhat correlated. The zoning of a particular element shown in a map was in fact evidence for the presence of that particular element in the stone. Therefore, the elements mentioned above were present in this piece of stone, which might not be deduced from a broad beam PIXE bulk analysis because of their low concentrations.
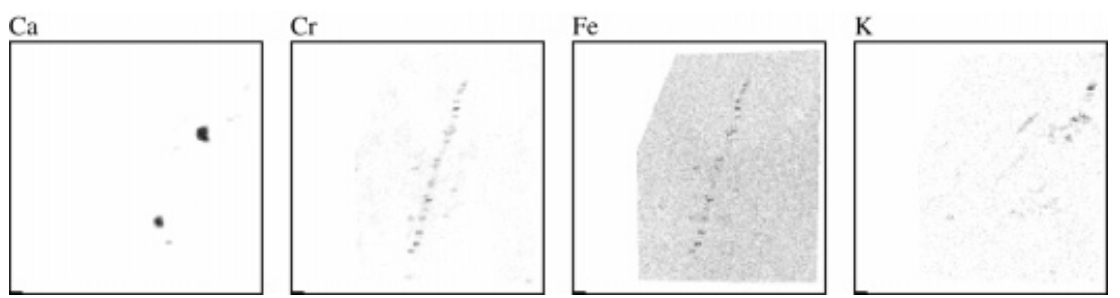

Figure 5. Nuclear microscopic maps of a Zambian emerald (ZB13). Two calcite/dolomite inclusions are shown in the Ca map, chromite and magnetite are identified across the middle of the scan from top to bottom as shown in the $\mathrm{Cr}$ and Fe maps, mica inclusions are shown in the top right-hand corner of the $\mathrm{K}$ map and the biotite inclusion is shown in the $\mathrm{Fe}$ and $\mathrm{K}$ maps. Charge $=0.031 \mu \mathrm{C}$; the square grid represents an area of $3.6 \times 3.6 \mathrm{~mm}$. 

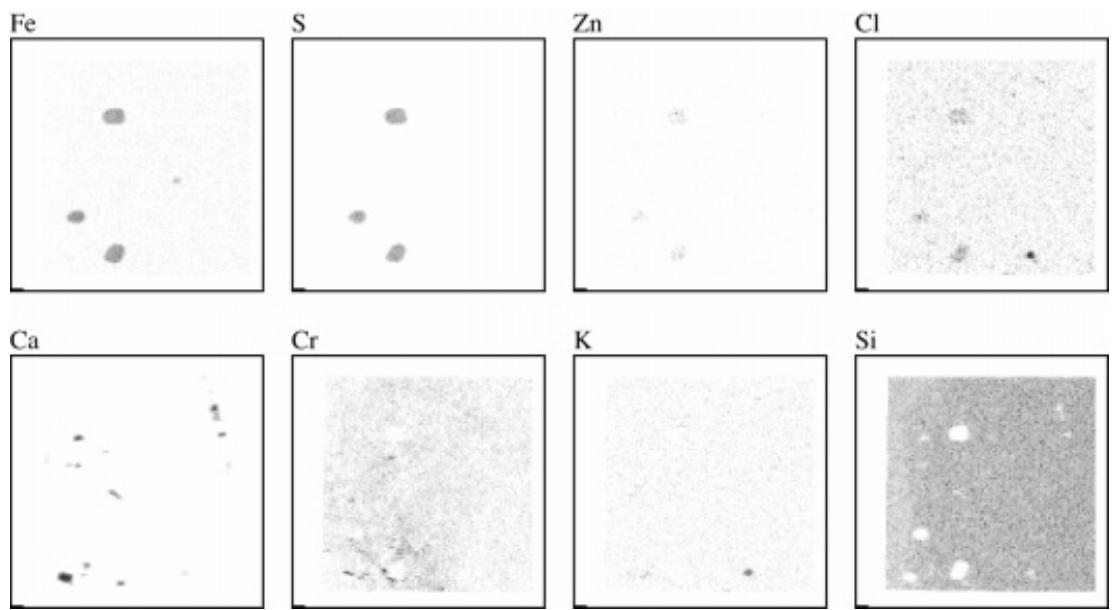

Figure 6. Nuclear microscopic maps of a Zambian emerald (ZB19). A brine component is shown as the darkest spot near the lower edge of the $\mathrm{Cl}$ scan; calcite/dolomite inclusions are identified in the $\mathrm{Ca}$ map; chromite inclusions are shown on the left of the $\mathrm{Cr}$ map and a magnetite inclusion is shown besides the three darkest spots in the Fe map; pyrite inclusions are identified in the Fe map (the three darkest spots) and the S map. The pyrite inclusions might be accompanied by the mineral sphalerite/wurtzite (ZnS). The origin of the correlation between the pyrite inclusions with the element $\mathrm{Cl}$ is not yet known. Charge $=0.032 \mu \mathrm{C}$; the square grid represents an area of $3.6 \times 3.6 \mathrm{~mm}$.
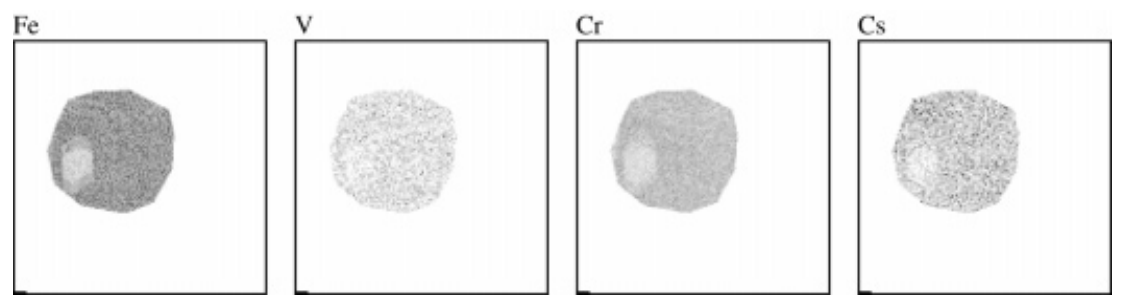

Figure 7. Nuclear microscopic maps of a Pakistan emerald (PK1). Color zoning and elemental zoning are observed, which consist of a sharply defined paler hexagonal core at the lower left region of the scan surrounded by a more saturated shell. Charge $=0.101 \mu \mathrm{C}$; the square grid represents an area of $2 \times 2 \mathrm{~mm}$.
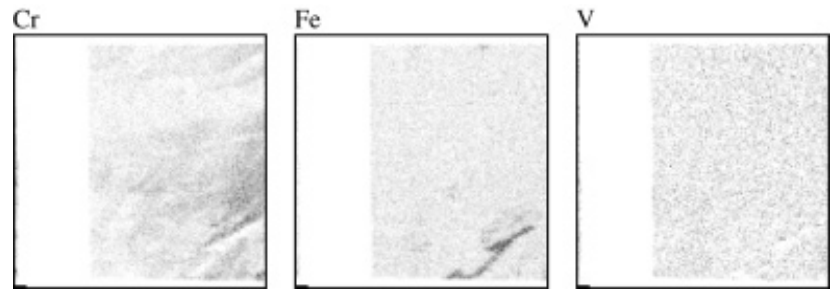

Figure 8. Nuclear microscopic maps of a Pakistan emerald (PK4). A cloudy color zoning is observed in the $\mathrm{Cr}$ map. Charge $=0.051 \mu \mathrm{C}$; the square grid represents an area of $3.6 \times 3.6 \mathrm{~mm}$.

\section{Brine components}

As mentioned before, cavities in Colombian stones were originally filled with a single-phase brine with a salt content of approximately $40 \mathrm{wt} \% \mathrm{Cl}$ and $\mathrm{Na}$ with $\mathrm{Ca}$, $\mathrm{K}$, etc. ${ }^{4}$ It is also interesting to note from our PIXE maps that $\mathrm{Cl}$ is always correlated with one or more of the elements $\mathrm{K}, \mathrm{Ca}$ and $\mathrm{S}$, in other natural emeralds and in synthetic emeralds. Therefore, it is natural to treat the correlations between $\mathrm{Cl}$ and $\mathrm{K}, \mathrm{Cl}$ and $\mathrm{Ca}$ or uncorrelated $\mathrm{Cl}$ as brine components. It is known that the minerals halite $(\mathrm{NaCl})$ and sylvite $(\mathrm{KCl})$ are often accompanied by anhydrite $\left(\mathrm{CaSO}_{4}\right)$, gypsum $\left(\mathrm{CaSO}_{4} \cdot 2 \mathrm{H}_{2} \mathrm{O}\right)$, kainite $\left(\mathrm{KMg}\left[\mathrm{Cl} \mid \mathrm{SO}_{4}\right] \cdot 3 \mathrm{H}_{2} \mathrm{O}\right)$, kieserite
$\left(\mathrm{MgSO}_{4} \cdot \mathrm{H}_{2} \mathrm{O}\right)$ and polyhalite $\left(\mathrm{K}_{2} \mathrm{Ca}_{2} \mathrm{Mg}\left[\mathrm{SO}_{4}\right]_{4} \cdot 2 \mathrm{H}_{2} \mathrm{O}\right){ }^{7}$ Therefore, the correlation between $\mathrm{Cl}$ and $\mathrm{S}$, although usually a weak one, may just show that $S$ is also present in the brine. In fact, brine components were observed in most emeralds from our PIXE maps, no matter whether natural or synthetic, and no matter what the localities or the manufacturers were, except for the very clean Chatham and the Lechleitner stones.

Brine components were identified in the Colombian stone CB17 (Fig. 2), which showed strong correlations between $\mathrm{Cl}$ and $\mathrm{K}$, and weaker correlations with $\mathrm{Ca}$ and $\mathrm{S}$; in the Zambian stone ZB19 (Fig. 6), being shown as the darkest spot near the lower edge of the $\mathrm{Cl}$ scan; in the Russian flux stone RF2 (Fig. 10), being shown as the correlation of the dark spot in the $\mathrm{Cl}$ map with the dark spot shown in the $\mathrm{K}$ map, and the weak correlation with that shown in the Ca map.

Brine components were also found in the Biron hydrothermal stone BH1 (Fig. 11), and these were the only features that could be identified from all its maps. It had been concluded ${ }^{2}$ that $\mathrm{Cl}$ was detected in all hydrothermal emeralds and was believed to come from the chloride hydrate $\left(\mathrm{CrCl}_{3} \cdot 6 \mathrm{H}_{2} \mathrm{O}\right)$ that was used to supply $\mathrm{Cr}$ as a coloring agent. ${ }^{3}$ However, correlations between $\mathrm{Cr}$ and $\mathrm{Cl}$ were not identifiable in our maps. Optical microscopic inspection of the stone confirmed that it was very clean but revealed very tiny white dust-like inclusions just below the table facet for the scans. These might be the brine 

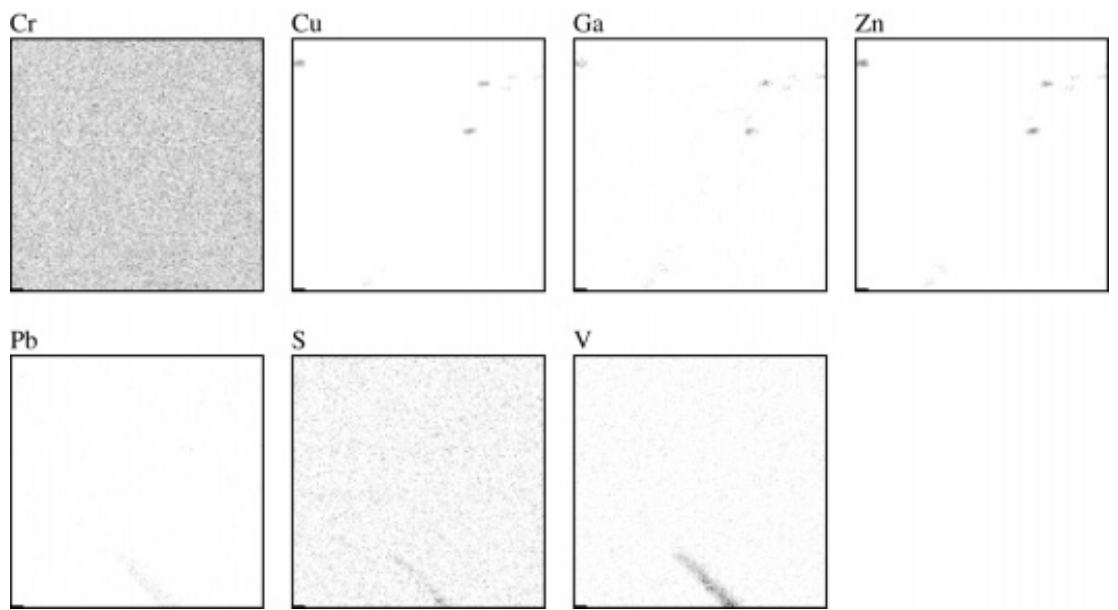

Figure 9. Nuclear microscopic maps of a Russian flux-grown synthetic emerald (RF1). The flux residue for $\mathrm{PbO}-\mathrm{V}_{2} \mathrm{O}_{5}$ is positively identified in the $\mathrm{Pb}$ and $\mathrm{V}$ maps. The correlation between $\mathrm{S}$ with $\mathrm{Pb}$ and $\mathrm{V}$ might be due to the addition of the flux in the form of a sulfate or a sulfur-bearing mineral. Correlations among the elements $\mathrm{Cu}$, $\mathrm{Ga}$ and $\mathrm{Zn}$ indicate that these nutrients were added. Charge $=0.075 \mu \mathrm{C}$; the square grid represents an area of $3.6 \times 3.6 \mathrm{~mm}$.
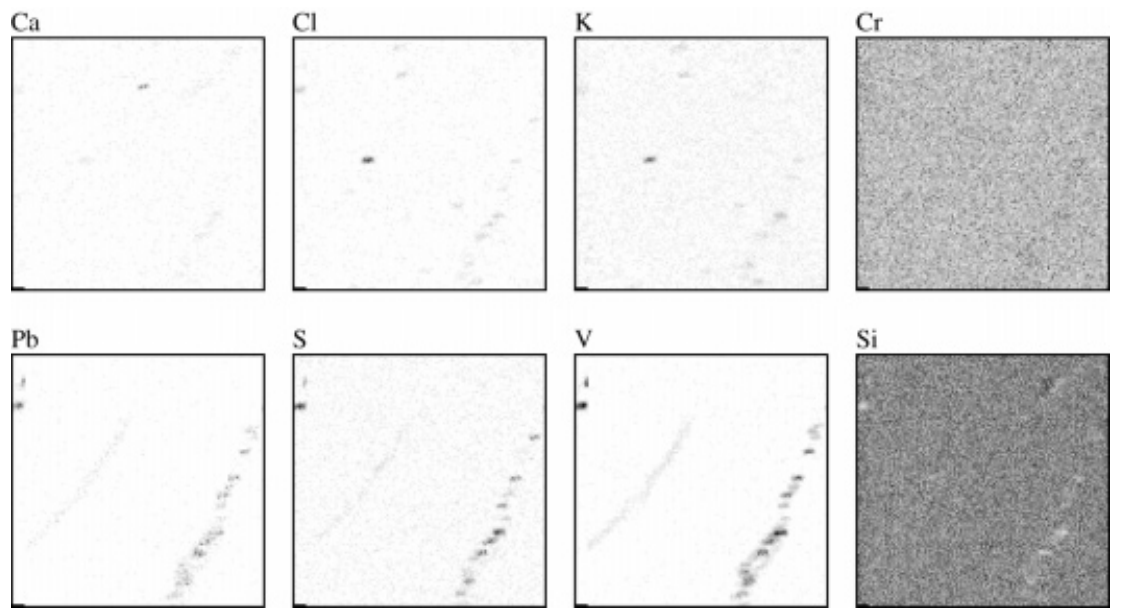

Figure 10. Nuclear microscopic maps of a Russian flux-grown synthetic emerald (RF2). The flux residue for $\mathrm{PbO}-\mathrm{V}_{2} \mathrm{O}_{5}$ is positively identified in the $\mathrm{Pb}$ and $\mathrm{V}$ maps. The correlation between $\mathrm{S}$ with $\mathrm{Pb}$ and $\mathrm{V}$ might be due to the addition of the flux in the form of a sulfate or a sulfur-bearing mineral. Along with the flux residues revealed in the $\mathrm{Pb}$ and $\mathrm{V}$ maps, added nutrients $\mathrm{Ca}, \mathrm{K}, \mathrm{S}, \mathrm{V}, \mathrm{Cr}$ and $\mathrm{Cl}$ are also identified. Brine components are identified as the correlation of the dark spot in the $\mathrm{Cl}$ map with the dark spot shown in the $\mathrm{K}$ map, and the weak correlation with that shown in the Ca map. Charge $=0.073 \mu \mathrm{C}$; the square grid represents an area of $3.6 \times 3.6 \mathrm{~mm}$.

components mentioned above but confirmation was still not possible.

\section{Calcite/dolomite}

Calcite is $\mathrm{CaCO}_{3}$ whereas dolomite is $\mathrm{CaMg}\left(\mathrm{CO}_{3}\right)_{2}$, so these are defined to be dots in the Ca map alone and no
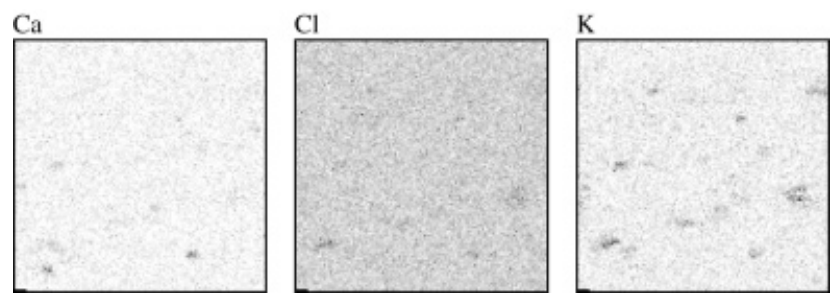

Figure 11. Nuclear microscopic maps of a Biron hydrothermal-grown synthetic emerald (BH1). The only features that can be identified are the brine components. Charge $=0.063 \mu \mathrm{C}$; the square grid represents an area of $3.6 \times 3.6 \mathrm{~mm}$. other maps. In fact, from our maps, we cannot differentiate between calcite and dolomite, because we do not have information on Mg. Two calcite/dolomite inclusions were identified in the Zambian stone ZB13 (Fig. 5), which were shown in the Ca map and were confirmed by optical microscopic inspection. Calcite/dolomite inclusions were identified in the Zambian stoneZB19 (Fig. 6) from its Ca map.

\section{Chromite/magnetite}

Chromite is $(\mathrm{Fe}, \mathrm{Mg}) \mathrm{Cr}_{2} \mathrm{O}_{4}$ whereas magnetite is $\mathrm{Fe}_{3} \mathrm{O}_{4}$. Therefore, chromite is defined to be small dots which are shown in the Cr map, with or without simultaneous showups in the Fe map; magnetite is defined to be small dots which are shown in the Fe map. When chromite is present, it is difficult to tell whether magnetite is present or not. Only when dots show up in the Fe map but not in the $\mathrm{Cr}$ map can magnetite be identified without confusion. Chromite/magnetite inclusions were identified in four of 

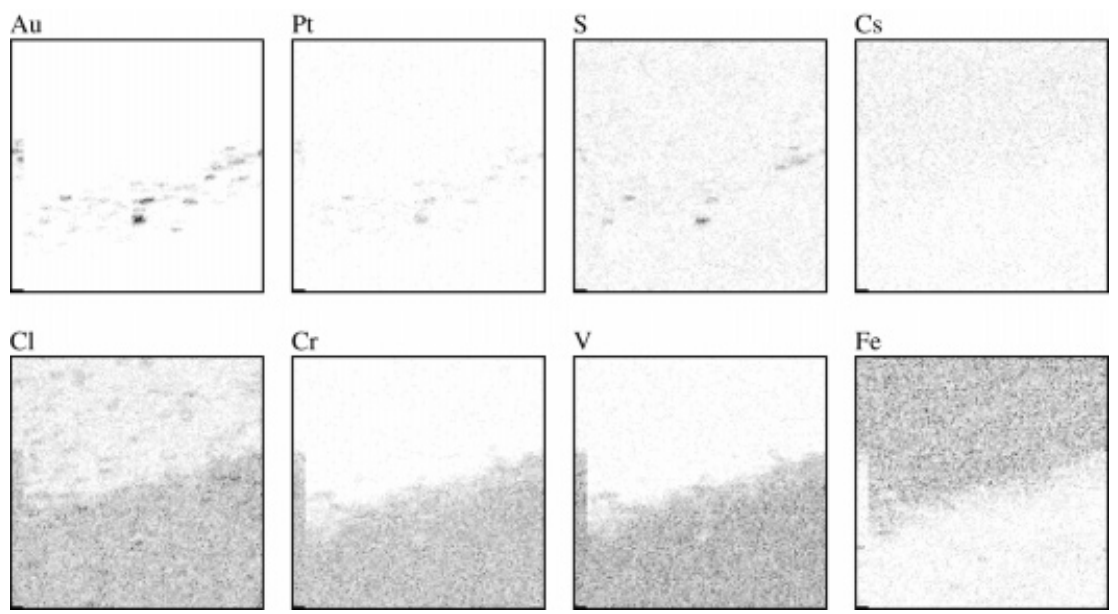

Figure 12. Nuclear microscopic maps of a Biron hydrothermal-grown synthetic emerald (BH2). The scans clearly identify the boundary between the seed and the hydrothermal-grown emerald, and show the presence of $\mathrm{Au}$ and $\mathrm{Pt}$, and also some excessive $\mathrm{S}$ here. The first two elements might have been used as the crucible for the synthetic growth of emeralds to take place. Charge $=0.071 \mu \mathrm{C}$; the square grid represents an area of $3.6 \times 3.6 \mathrm{~mm}$.
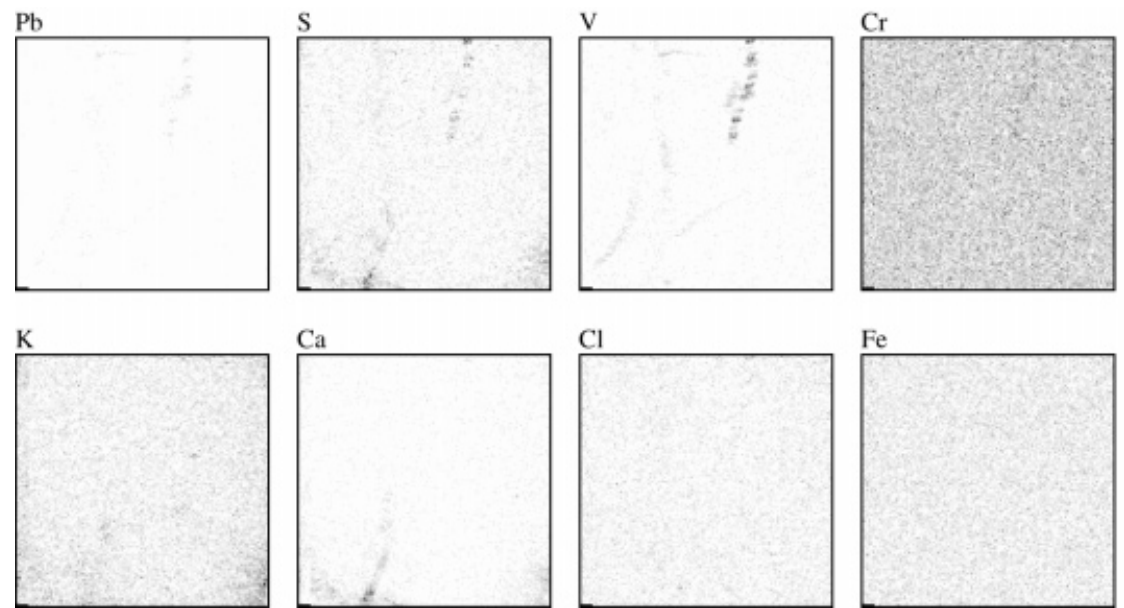

Figure 13. Nuclear microscopic maps of a Russian hydrothermal-grown synthetic emerald (RH1). It is surprising to find veil-like inclusions correlating $\mathrm{Pb}, \mathrm{V}$ and $\mathrm{S}$, which resemble those found in Russian flux-grown emeralds, because $\mathrm{Pb}$ is thought to be a flux component. The resemblance is not yet understood. Charge $=0.031 \mu \mathrm{C}$; the square grid represents an area of $3.6 \times 3.6 \mathrm{~mm}$.

our Zambian stones. In ZB11 (Fig. 4), the maps of $\mathrm{Cr}$ and $\mathrm{Fe}$ showed the presence of chromite and magnetite. The anticorrelation between the pattern with Si implied that this set of inclusions were rather near the surface. ${ }^{8}$ The identities of chromite and magnetite were confirmed under the microscope. In ZB13 (Fig. 5), chromite and magnetite were identified across the middle of the scan from top to bottom as shown in the $\mathrm{Cr}$ and $\mathrm{Fe}$ maps. The inclusions of chromite and magnetite were confirmed by optical microcsopic inspection. In ZB19 (Fig. 6), chromite inclusions were shown on the left of the $\mathrm{Cr}$ map while a magnetite inclusion was shown beside the three darkest spots in the Fe map. The chromite and magnetite were confirmed optically.

\section{Pyrite}

Pyrite is $\mathrm{FeS}_{2}$, and is thus defined to be dots simultaneously clearly shown in the $\mathrm{Fe}$ and $\mathrm{S}$ maps. Pyrite inclusions were identified in the Zambian stone ZB19 (Fig. 6) as shown in the Fe map (the three darkest spots) and the S map. The pyrite inclusions were confirmed optically. It was noticed that the pyrite inclusions were also shown in the maps of $\mathrm{Zn}$ and $\mathrm{Cl}$. On checking the minerals with $\mathrm{Zn}$ contents usually accompanying pyrite, ${ }^{7}$ this might imply the mineral sphalerite/wurtzite $(\mathrm{ZnS})$. However, the mineral contributing the element $\mathrm{Cl}$ is not yet known, but is likely to come from remnant of the brine.

Pyrite crystals were seldom identified in our samples (only in two Zambian stones) which might be due to the following reason. Since almost all of our samples were cut stones, and the cutting had been performed in such a way as to keep the large pieces of pyrite crystals away from the table facet to make the stone more beautiful. At the same time, however, our irradiation of the samples took place on the table facet if the stone was not a cabochon or rough stone, so the pyrite crystals could escape from the irradiation most of the time. For example, optical inspection of the emerald $\mathrm{ZB} 11$ revealed the presence of large pyrite crystals somewhere beneath the table facet, but these did not show up in the PIXE maps. Only when the crystals were sufficiently close to the surface of the 
Table 1. Summary of the criteria for the identification of inclusions in emeralds for the traditional optical microscopic method and for the nuclear microscopic method, with the sample stones listed in which the nuclear microscopic identifications have been made

Inclusion

Color zoning

Calcite and dolomite

Chromite

Magnetite

Pyrite

Mica

Feldspar

Flux residues

Nutrient residues

Seed

Different appearance of the seed plate crystal

Not observed

Not observed

Features in micro-PIXE maps

Zoning of chromophore

elements $\mathrm{Cr}, \mathrm{V}$, Fe

Dots in Ca map alone

faces; transparent and colorless

Dolomite: rhombohedral; similar to

calcite, bread-crumb like, often in cluster

Cubic; often as black opaque minute

cubic crystal and in cluster, associated

with dolomite, difficult to separate from

magnetite

ubic; similar to chromite, opaque,

formed in cluster

Cubic; brassy metallic appearance,

opaque, can appear in dodecahedra

Monoclinic; often appears flaky and

transparent; phlogopite and biotite

slightly tinted brown

Monoclinic; tabulated appearance,

colorless or white, others tinted green,

red, pink or yellow

Coarse to fine whitish and wispy veil-like appearance

Fine veil-like appearance

Elemental zoning

Brine component
Small dots in Cr map, with possible simultaneous show up in Fe map

Small dots in Fe map alone

Dots in $\mathrm{Fe}$ and $\mathrm{S}$ maps

simultaneously

Phlogopite and muscovite: dots

in $\mathrm{K}$ map alone Biotite: dots in

$\mathrm{K}$ and $\mathrm{Fe}$ maps simultaneously

Orthoclase and plagioclase:

dots in $\mathrm{K}$ and $\mathrm{Ca}$ maps

simultaneously

Veils in maps of flux elements

such as $\mathrm{Mo}, \mathrm{Pb}, \mathrm{Bi}$ and $\mathrm{W}$

Veils or clusters in elemental

maps, with possible

simultaneous show-up in maps

of flux elements

The same boundary identified

in almost all maps; features

may be identified in elemental

maps of exotic elements such

as $\mathrm{Au}, \mathrm{Pt}$

Zoning of non-chromophore

elements

Correlations between the $\mathrm{Cl}$

map with the $\mathrm{K}$ or Ca map, or

features in the $\mathrm{Cl}$ map alone
Sample stones (Fig. No.)

CB9 (1), PK1 (7),

PK4 (8)

ZB13 (5), ZB19 (6)

ZB11 (4), ZB13 (5) ZB19 (6)

ZB11 (4), ZB13 (5),

ZB19 (6)

ZB19 (6)

ZB13 (5)

RF1 (9), RF2 (10)

$\mathrm{RH} 1(13)$

RF1 (9), RF2 (10)

$\mathrm{RH} 1$ (13)

$\mathrm{BH} 2(12)$

ZB9 (3), PK1 (7)

CB17 (2), ZB19 (6)

RF2 (10), BH1 (11) table facet could they be revealed in the PIXE maps. Even in this case, the number of pyrite crystals shown in the maps was far smaller than that observed optically.

\section{Mica}

Mica is a group of silicates with the general formula $\mathrm{XY}_{2-3} \mathrm{Z}_{4} \mathrm{O}_{10}(\mathrm{OH}, \mathrm{F})_{2}$, where $\mathrm{X}=\mathrm{K}, \mathrm{Ca}, \mathrm{Ba},\left(\mathrm{H}_{3} \mathrm{O}\right), \mathrm{Na}$, $\left(\mathrm{NH}_{4}\right), \mathrm{Y}=\mathrm{Mg}, \mathrm{Fe}^{2+}, \mathrm{Fe}^{3+}, \mathrm{Al}, \mathrm{Cr}^{3+}, \mathrm{Li}, \mathrm{Mn}^{2+}, \mathrm{V}^{3+}, \mathrm{Zn}$ and $\mathrm{Z}=\mathrm{Al}, \mathrm{Fe}^{3+}, \mathrm{Be}, \mathrm{Si}^{9}$ The more common micas are paragonite, $\mathrm{NaAl}_{2}\left[(\mathrm{OH}, \mathrm{F})_{2} \mid \mathrm{AlSi}_{3} \mathrm{O}_{10}\right]$, phlogopite, $\mathrm{KMg}_{3}\left[(\mathrm{~F}, \mathrm{OH})_{2} \mid \mathrm{AlSi}_{3} \mathrm{O}_{10}\right]$, biotite, $\mathrm{K}(\mathrm{Mg}, \mathrm{Fe})_{3}\left[(\mathrm{OH}, \mathrm{F})_{2} \mid\right.$ $\left.\mathrm{AlSi}_{3} \mathrm{O}_{10}\right]$, and muscovite, $\mathrm{KAl}_{2}\left[(\mathrm{OH}, \mathrm{F})_{2} \mid \mathrm{AlSi}_{3} \mathrm{O}_{10}\right]$. Within these, paragonite will not show up in our maps, phlogopite and muscovite will show up in the $\mathrm{K}$ map alone and biotite will show up in both the $\mathrm{K}$ and $\mathrm{Fe}$ maps. Phlogopite/muscovite were found in emeralds from all localities in the present investigation, but biotite was found only in Zambian emeralds. For example, mica inclusions were identified in the Zambian stone ZB13 (Fig. 5) as shown in the top right hand-corner of the $\mathrm{K}$ map, and the biotite inclusion shown in the $\mathrm{Fe}$ and $\mathrm{K}$ maps.

\section{Feldspar}

Feldspar can be divided into orthoclase feldspar, $\mathrm{K}\left[\mathrm{AlSi}_{3} \mathrm{O}_{8}\right]$, and plagioclase feldspar, and the latter can be further divided into albite, $\mathrm{Na}\left[\mathrm{AlSi}_{3} \mathrm{O}_{8}\right]$, and anorthite, $\mathrm{Ca}\left[\mathrm{Al}_{2} \mathrm{Si}_{2} \mathrm{O}_{8}\right]$. If present, the orthoclase feldspar will be confused with the phlogopite/muscovite micas, and the anorthite will be confused with the calcite/dolomite. Although feldspars have been found in emeralds from different localities, ${ }^{10}$ these are less frequent than the corresponding micas and calcite/dolomite, so we believe that the effects of not considering feldspars are small. Nevertheless, since the orthoclase and plagioclase feldspars accompany each other, a correlation between $\mathrm{K}$ and $\mathrm{Ca}$ only may imply a feldspar inclusion.

\section{Flux residues/nutrient residues}

It is well known that a typical internal feature of fluxgrown emerald is the veil-like flux residues. Therefore, the flux residues are defined as features shown in the maps of possible flux elements. In the past, the oxides of Mo, $\mathrm{Pb}$ and $\mathrm{Bi}$ have been used as flux components. The most 
suitable flux used for the growth of gemstones appears to be one with high contents of $\mathrm{PbO}, \mathrm{MoO}_{3}$ or $\mathrm{Bi}_{2} \mathrm{O}_{3}{ }^{11}$ It has also been suggested that the chemical behavior of $\mathrm{W}$ is very similar to that of Mo and can also be used as a flux component. ${ }^{12}$ The flux used for Russian flux-grown emeralds is $\mathrm{PbO}-\mathrm{V}_{2} \mathrm{O}_{5} \cdot{ }^{13}$ Nutrient residues are defined to be the chemical elements which are not themselves flux elements but exist in a veil or cluster with or without the flux elements.

Flux residues/nutrient residues were identified in two of our Russian flux stones, RF1 (Fig. 9) and RF2 (Fig. 10). It has been documented that the flux used in the Russian flux-grown emeralds is $\mathrm{PbO}-\mathrm{V}_{2} \mathrm{O}_{5}$, which is heated together with the nutrients and the coloring agents to $1250{ }^{\circ} \mathrm{C}$ in a platinum crucible for the growth of the crystals. ${ }^{13}$ From the maps, the flux $\mathrm{PbO}-\mathrm{V}_{2} \mathrm{O}_{5}$ was positively identified. $\mathrm{Pb}$ was not observed in the elemental maps for natural emeralds. Furthermore, $\mathrm{S}$ was also found to correlate with $\mathrm{Pb}$ and $\mathrm{V}$. The reason might be that the flux had been added in the form of a sulfate or a sulfurbearing mineral had been added together with the flux. Correlations among the elements $\mathrm{Cu}, \mathrm{Ga}$ and $\mathrm{Zn}$ were also observed for RF1, which represent part of the nutrients added for the Russian growth stones. For RF2, along with the flux residues revealed in the $\mathrm{Pb}$ and $\mathrm{V}$ maps, added nutrients $\mathrm{Ca}, \mathrm{K}, \mathrm{S}, \mathrm{V}, \mathrm{Cr}$ and $\mathrm{Cl}$ were also identified. The flux residues could also be seen optically.

Although flux-filled $\left(\mathrm{MoO}_{3}\right)$ tubes was said to be present in Lennix stones, ${ }^{6}$ these were not observed from our maps for the Lennix stone. It was surprising to find veil-like inclusions correlating $\mathrm{Pb}, \mathrm{V}$ and $\mathrm{S}$ in the Russian hydrothermal stone RH1 (Fig. 13) and two other Russian hydrothermal stones, which resembled those found in Russian flux-grown emeralds, because $\mathrm{Pb}$ is thought to be a flux component. It was noticed that $\mathrm{Pb}$ was not identified in other hydrothermal-grown emeralds studied in the present investigation, i.e. the Biron and the Lechleitner emeralds. The resemblance is not yet understood.

It was interesting to note that a lot of the flux or nutrient residues had correlations with the brine components $(\mathrm{K}$, $\mathrm{Ca}, \mathrm{Cl})$. The correlations among these elements might mean that brine components had been artificially added. However, it was noted that brine components were also common in natural stones, and it was also observed for natural stones that there were correlations between the brine components $(\mathrm{K}, \mathrm{Ca}, \mathrm{Cl})$ and other elements, such as $\mathrm{Cu}, \mathrm{Zn}, \mathrm{Fe}$ and $\mathrm{Ti}$ (mostly in Colombian stones).

Along the flux veils of Gilson and Russian flux-grown emeralds, elements such as the brine components $\mathrm{K}, \mathrm{Ca}$, $\mathrm{Cl}$ and $\mathrm{S}$ and the chromophore $\mathrm{Cr}$ had been identified. Nutrient residues correlating the elements K, V, Fe and $\mathrm{Cr}$ had also been found. As mentioned above, an interesting cluster containing specks of the elements $\mathrm{Zn}, \mathrm{Cu}$ and Ga was recorded in the Russian flux stone RF1. The Lennix flux grown stone contained specks correlating the brine components $\mathrm{K}, \mathrm{Ca}, \mathrm{Cl}$ and $\mathrm{S}$ with $\mathrm{Cu}$. For the Biron hydrothermal emeralds, a very patchy pattern had been obtained for the brine componens $\mathrm{K}, \mathrm{Ca}$ and $\mathrm{Cl}$, which had a very strong correlation between $\mathrm{K}$ and $\mathrm{Ca}$ but a weaker correlation with $\mathrm{Cl}$. The brine components were also found to correlate with $\mathrm{Fe}$ and $\mathrm{Ti}$. The veil-like inclusions correlating $\mathrm{Pb}, \mathrm{V}$ and $\mathrm{S}$ observed in the Russian hydrothermal-grown emeralds were also correlated with the brine components $\mathrm{K}, \mathrm{Ca}$ and $\mathrm{Cl}$ and also the chromophore element $\mathrm{Cr}$.

\section{Seed crystal}

A seed was clearly identified from the scans for the Biron hydrothermal stone $\mathrm{BH} 2$ (Fig. 12), which proved the hydrothermal synthetic nature of the emerald. The scans clearly identified the boundary between the seed and the hydrothermal grown emerald, and showed the presence of $\mathrm{Au}$ and $\mathrm{Pt}$, and also some excessive $\mathrm{S}$ here. The first two elements might have been used as the crucible for the synthetic growth of emeralds to take place. Careful examination of the boundary under the microscope also revealed a layer with metallic luster which was linked to $\mathrm{Au}$ and Pt.

\section{CONCLUSIONS}

Using maps recorded by micro-PIXE for different chemical elements for natural and synthetic emeralds, the power of this technique for revealing inclusions in emeralds was demonstrated, even for rough stones. The inclusions identified were color zoning/elemental zoning, brine components, calcite/dolomite, chromite/magnetite, pyrite, mica (biotite, phlogopite and muscovite), feldspar (orthoclase and anorthite of plagioclase), flux/nutrient residues for synthetic emeralds and seed crystal in hydrothermal emeralds.

Some criteria for discrimination between natural and synthetic emeralds were provided. The Chatham and the Lechleitner had nearly featureless maps, which were not observed for natural stones. The most informative inclusions for a synthetic stone were the flux residues or the nutrient residues. Natural stones had color zoning in general. Although there were also reports saying that different color zones had been identified in synthetic emeralds, these were not identified in our synthetic samples. Nonbiotic micas were absent in synthetic stones, but were present in natural stones from all localities.

In previous investigations, $\mathrm{Cl}$ was not detected in all natural emeralds ${ }^{1,2}$ but was detected in all the hydrothermal emeralds, ${ }^{2}$ which was believed to come from the chloride hydrate $\left(\mathrm{CrCl}_{3} \cdot 6 \mathrm{H}_{2} \mathrm{O}\right)$ used to supply $\mathrm{Cr}$ as a coloring agent. ${ }^{3}$ In the present investigation, $\mathrm{Cl}$ was identified as a brine component in most of the natural and also the synthetic stones.

Micro-PIXE was demonstrated to be a superb method for in situ studies of minerals. Compared with electron microprobe analysis, PIXE can examine minerals at greater depths from the crystal surface and has much higher sensitivity (much lower limits of detection). In particular, during the present investigation, sphalerite/wurtzite were found to accompany pyrite in Zambian stones. These minerals have not been found for emeralds before. However, we must still be cautious of pile-up effects.

\section{Acknowledgement}

K. N. Yu acknowledges the hospitality of the Department of Physics of the National University of Singapore during his stay. 


\section{REFERENCES}

1. Hänni HA. J. Gemmol. 1982; 18: 138

2. Stockton CM. Gems Gemol. 1984; Fall: 141-145.

3. Nassau K. Gems Made by Man. Chilton: Radnor, PA, 1980.

4. Boshart G. J. Gemmol. 1991; 22: 7.

5. Watt F, Orlic I, Loh KK, Sow $\mathrm{CH}$, Thong $\mathrm{P}$, Liew SC Osipowicz T, Choo TF, Tang SM. Nucl. Instrum. Methods B 1994; 85: 708.

6. Graziani G, Gubelin E, Martini M. Gems Gemol. 1987; Fall: 140.

7. Schumann W (translated by Reinersmann EE). Minerals of the World. Sterling Publishing: New York, 1992.
8. Osipowicz T, Tay TS, Orlic I, Tang SM, Watt F. Nucl. Instrum. Methods B 1995; 104: 590.

9. Roberts WL, Campbell TJ, Rapp GR Jr. Encyclopedia of Minerals. Van Nostrand Reinhold: New York, 1990.

10. Schwarz D, Kanis J, Kinnaird J. J. Gemmol. 1996; 25: 117.

11. Notes for Diploma Course, Gemmological Association and Gem Testing Laboratory of Great Britain: London, 1987.

12. Schrader HW. J. Gemmol. 1983; 18: 530.

13. Koivula JI, Keller PC. Gems Gemol. 1985; Summer: 79. 